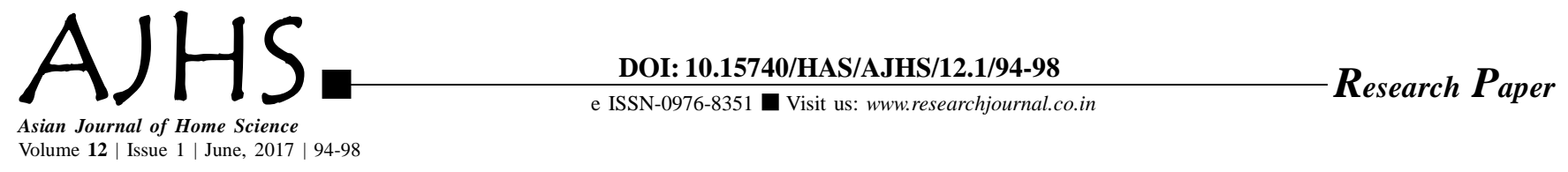

\title{
Occupational health hazards of the female construction workers
}

\author{
KUMARI AMRITA SINHA, APRAJITA KUMARI AND RITU GUPTA
}

Received: 09.01.2017; Revised: 01.04.2017; Accepted: 18.04.2017

See end of the paper for authors' affiliations KUMARI AMRITA SINHA Department of Family Resource Management, College of Home Science, Punjab Agricultural University, LUDHIANA (PUNJAB) INDIA

Email : amrita.sinha726@gmail. com
ABSTRACT : Construction work involves several manual material handling tasks including both skilled and unskilled activities. Females are generally engaged in the unskilled works where as skilled works are completely done by male workers. Females are engaged in carrying different construction materials like brick, sand, cement and concrete. They use to carry all these materials on their head putting undue stress on their body. Present study was focused on studying the activities profile of women on construction site and assessing their health hazards and musculoskeletal problems. For the purpose of study, 10 female construction workers working within the campus of Punjab Agricultural University's were selected. Their activity profile and health hazards were studied with the help of questionnaire whereas their musculoskeletal discomforts were studied with the help of REBA and the risk assessment scores for musculoskeletal discomfort in different body parts. Results revealed that the female workers work for an average of 9.2 hours per day with a continuous working hour of 4.1 hour. REBA analysis revealed that brick lifting was the most tedious activity as its activity score was 12 followed by brick landing (11) and brick carrying (9). Further the risk assessment scale depicted that pain was felt in the upper arms, neck, thighs, head, shoulders, wrists, low back, feet, lower arms, ankles, mid back, legs, upper back, fingers, buttock and palm. Numbness was felt in fingers and palms; Stiffness in neck and feet; tingling sensation in palms and weakness in upper arms, thighs, feet, legs, shoulder and upper back. Therefore, it can be concluded that female construction workers face high level of physical stress due to their occupation. They have to perform several hazardous activities among which brick carrying is the most frequent and most tedious task.

KEY WORDS: Brick carrying, Female construction workers, Occupational health hazards, REBA, Risk assessment

HOW TO CITE THIS PAPER : Sinha, Kumari Amrita, Kumari, Aprajita and Gupta, Ritu (2017). Occupational health hazards of the female construction workers. Asian J. Home Sci., 12 (1) : 94-98, DOI: 10.15740/HAS/AJHS/12.1/94-98. 